IMPERFORATE ANUS :

\title{
SOME OBSERVATIONS REGARDING DIAGNOSIS OF THE LEVEL OF OBSTRUCTION
}

BY

\author{
A. W. WILKINSON, F.R.C.S.Ed.
}

\section{(From the Department of Clinical Surgery, University of Edinburgh and the Royal Hospital for Sick Children, Edinburgh)}

In determining the precise method of treatment and prognosis in cases of imperforate anus much depends on the level at which the blind end of the rectum lies. Where the obstruction is membranous there is usually little difficulty in diagnosis, a bluish bulge being present where the anal opening should be or appearing there when the child cries; the treatment of this type by cruciate incision and subsequent bouginage is both simple and effective. It is more common, however, to find an obstruction at a somewhat higher level, the blind end of the rectum being just so high that the contained meconium does not show through the intervening and overlying skin tissues, or at varying levels up to the brim of the pelvis. Unless there is an associated urogenital fistula intestinal obstruction will be complete. Provided that the level of the blind end is not too high it is possible to bring down the rectum and suture it to the skin of the perineum per primam. When the rectum ends at a high level it is difficult to find the stump in the newly-born child, and attempts at primary proctoplasty are dangerous and difficult; the wiser course in such cases is to carry out colostomy only and defer the plastic operation. It is of value therefore to have accurate knowledge of the level of the blind end before deciding on the operative approach.

Wangensteen and Rice (1930) have described an ingenious method of determining the relationship of the perineal skin and the blind end of the rectum. The pelvis and abdomen are X-rayed while the child is held inverted, a metal marker being placed on the perineum. The gas in the colon rises and outlines the blind end of the rectum, the relation of which to the perineal marker may then be judged. It has been pointed out by Ladd and Gross (1941) that caution must be exercised in the interpretation of such films since the gas may not have reached the blind end of the rectum at the time of examination. They quote two cases in which at four and eight hours after birth it had reached only the terminal ileum and mid-transverse colon respectively leading them erroneously to believe that obstructions existed at these points. They stated that 'before fifteen to twenty hours of age the absence of gas in the rectum cannot be taken as evidence of intestinal or colonic obstruction. However, by the end of the first day of life an x-ray picture of the abdomen is an accurate method of determining the position of the blind rectal pouch.'

In view of this the following case appears to be of importance.

\section{Case record}

The patient was a full-term male baby $5 \mathrm{lb} .15 \frac{1}{2} \mathrm{oz}$. in weight (spontaneous delivery, vertex, L.O.A. labour lasting $7 \frac{1}{2}$ hours), well-developed and of healthy appearance except for the following features: The anus was represented by a shallow wrinkled depression about a $\frac{1}{4}$ in. in depth, no bluish membrane being present; both testicles were fully descended and lying in the scrotum the median line of which was shallowly cleft. The penis was well developed, but the prepuce could not be retracted. A fine red line ran along the median ventral surface of the penis and there were two dark purple thin-walled cysts, which appeared to contain blood, on the surface of the posterior third of the median raphe of the scrotum. A diagnosis of imperforate anus was made. X-ray examination thirty-six hours after birth in the upright and inverted positions with a perineal marker, showed no gas in rectum, the gas shadow reaching only to the level of the pelvic brim; there was considerable gas distension of the small intestine and colon, and an abnormality of the scrotum and coccyx (fig. 1, 2, 3).

At operation examination of the perineal depression showed some bulging during crying and a slight impulse was palpable. It was decided, therefore, to try needling in an attempt to locate the blind rectal pouch. A wide-bore needle was inserted, but no meconium could be aspirated; after withdrawal of the needle, however, a drop of meconium was blown out of the end of the needle. A deep cruciate incision was made into the floor of the anal depression and at a depth of half an inch meconium was encountered; about half a pint of very thick viscid meconium, under considerable tension, slowly escaped. A slight ooze of blood from the incision was readily controlled by a gauze dressing.

On the third day the proximal cyst on the scrotum ruptured and meconium escaped from the resultant fistula; a finger inserted into the anus caused a gush of meconium from the fistula. Subsequently, meconium and later faeces were passed both by the anus and the fistula, but urine was passed only from 


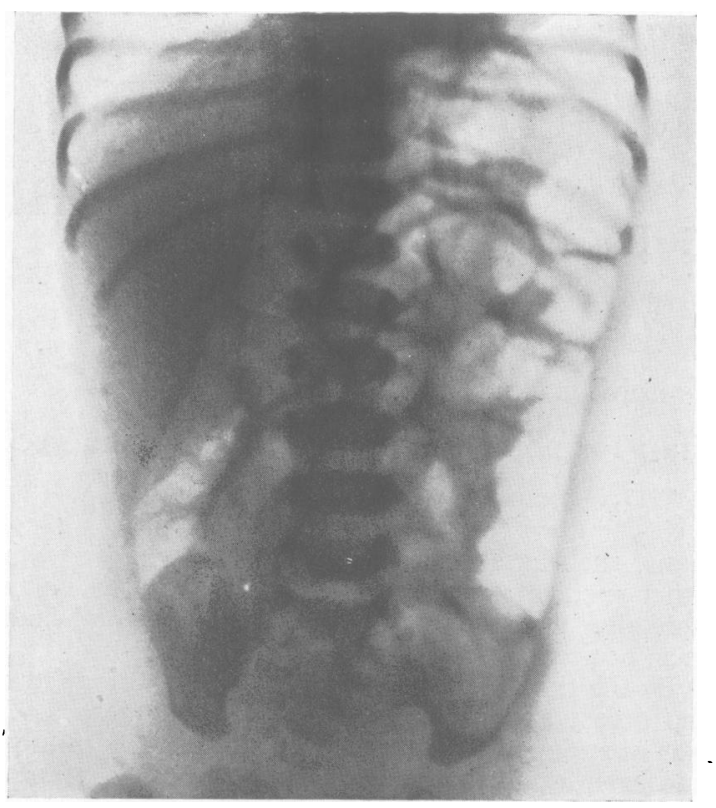

FIG. 1.-Antero-posterior x-ray in upright position showing gross distension of intestines with gas.

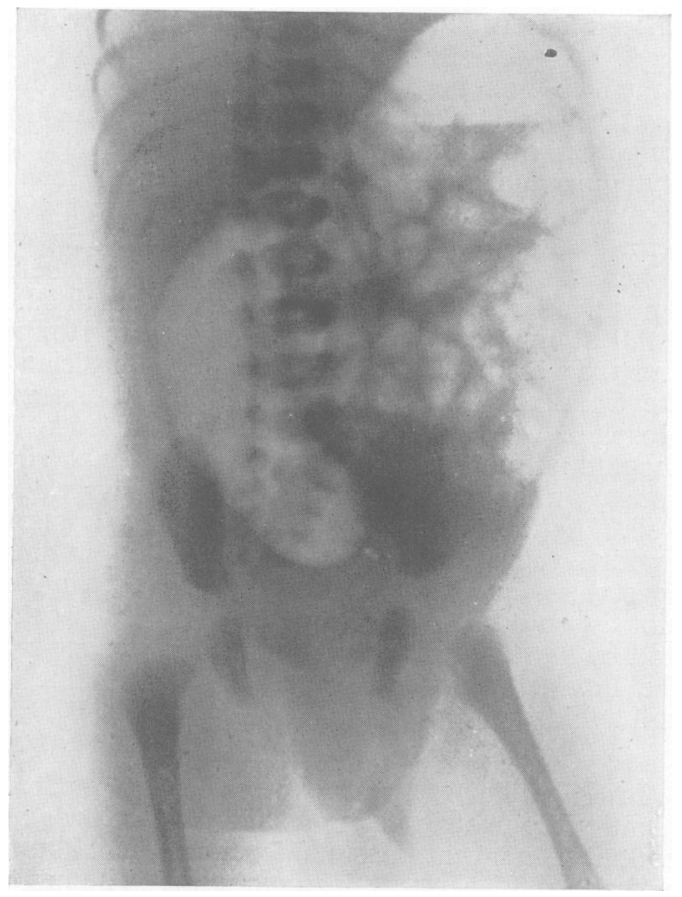

FIG. 2.-Oblique x-ray in upright position to show gross gaseous distension of intestines with clear definition of caecum and ascending colon below liver and the lower limit of the pelvic colon gas lying just above the pelvic brim.

the external urinary meatus and was never contaminated by meconium or faeces. Weekly dilatation by bougies increased the size of the anal passage and the proportion of faeces passed by this route. At the age of ten weeks the child died of pneumonia.

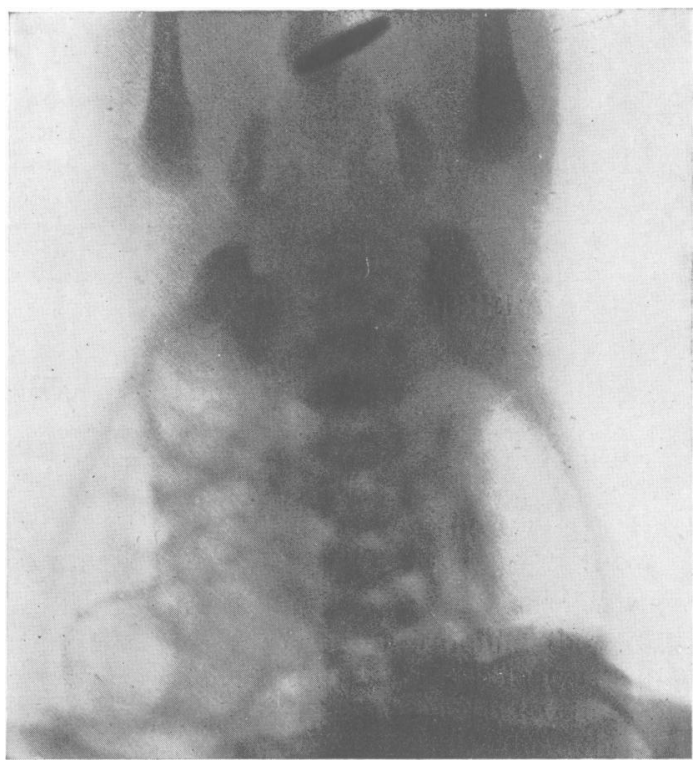

FIG. 3.-X-ray in inverted position to show marker on perineal dimple and the summit of the gas shadow in the pelvic colon. The larger shadow of the caecum and ascending colon can be distinguished by the shadow of the lower part of the right lobe of the liver.

\section{Comment}

The meconium was so thick and viscid that it is unlikely that it could have been rapidly displaced by gas. It is by no means unusual to find such viscid meconium, and it seems that the somewhat dogmatic statement of Ladd and Gross, that gas will be present at the rectal stump after twenty-four hours, requires modification. The advantages of cruciate incision or primary proctoplasty over colostomy are sufficient to make the former desirable whenever possible. It is recommended that, even in the absence of radiological signs of gas in the rectum, blind puncture and aspiration should be carried out with a wide-bore needle, when a little of the thick meconium may be sucked into the tip of the needle, although it may be too thick to be sucked into the barrel of the syringe. The rectoperineal fistula which subsequently developed in this patient opened further forwards than usual and was associated with a partial bifid scrotum; a similar condition was found once in a series of 118 fistulae recorded by Ladd and Gross (1941).

Thanks are due to Dr. Grant Allan, radiologist to the hospital, for examining the patient and allowing the reproduction of the $\mathrm{x}$-ray pictures.

\section{REFERENCES}

Ladd, W. E., and Gross, R. E. (1941). Abdominal surgery of infancy and childhood, Philadelphia, p. 166.

Wangensteen, O. M., and Rice, C. O. (1930). Ann. Surg., 92, 77. 